\title{
Effect of fibre suspension jet stability on alignment quality of discontinuous carbon fibre tapes
}

\author{
Z Liu*, TA Turner, KH Wong, SJ Pickering \\ Composites Research Group, Faculty of Engineering, the University of Nottingham, \\ Nottingham, NG7 2GX, United Kingdom \\ * To whom correspondence should be addressed: \\ email: zhe.liu1@nottingham.ac.uk
}

Keywords: Short fibre suspension, Shear flow, Fibre alignment, Jet break-up regimes

\section{Research highlights:}

- Jet stability has a significant influence on fibre orientation in hydrodynamic fibre alignment process.

- Fibre - Fibre interaction will affect the stability of short fibre suspension jets.

- A highly aligned fibre orientation is beneficial to suspension jet stability.

- Concave nozzle types (fire fighting type nozzle) can improve jet stability and fibre alignment quality which is validated by its shear rate profile from CFD analysis and experimental fibre orientation images.

\begin{abstract}
A hydrodynamic alignment process has been developed for converting discontinuous random carbon fibres into tapes with a highly aligned orientation distribution to greatly improve the applicability of recovered fibres to composite parts. In hydrodynamic alignment processes short fibres are aligned by the velocity gradient along the flow
\end{abstract}


direction in a convergent nozzle. Thereafter the jet of fibre suspension is deposited on a nylon mesh and the now redundant dispersion medium is drained away to leave an aligned fibre tape. The fundamental physical principles at work in the process have not been widely studied and are shown in the present work to greatly influence the properties of the resulting materials. In this work, the influence of suspension jet stability on the fibre orientation distribution was examined and the liquid jet break-up regime was determined. To explore the factors which can affect the suspension jet stability, different nozzle geometries, viscosities of dispersion media, fibre lengths and Reynolds numbers were applied in experimental work. The shear rate profiles inside different nozzles were simulated by Computational Fluid Dynamics methods and the results described in this paper.

\section{Introduction}

A hydrodynamic alignment process has been developed at the University of Nottingham, the inspiration for which was from paper making technology and work done at ERDE, the Explosives Research and Development Establishment UK, in the mid 1970's [1]. Significant amounts of research have been undertaken in the paper making industry to predict and control fibre orientation in a contracting channel (normally with the aim of reducing machine-direction bias). However, much less attention has been paid to the influence of the stability of fibre suspension jets on fibre orientation distributions. In this work, it has been found through careful video observation (by Vision Research Phantom V12.1 High Speed Camera with Nikon 60mm macro lens) of the fibre suspension jet that an unstable jet (Figure 1a) which splashes during deposition process will reduce fibre alignment. A varicose jet and air bubbles (Figure 1-b, c) can also misalign fibres. 
Therefore, a stable and cylindrical jet $(4 \leq$ Weber's number $<8)$ is required to maintain the pre-aligned fibre orientation.

\subsection{Liquid jet break-up regime}

Liquid jet research has been developed experimentally and theoretically for more than a century. Liquid jets are known to break-up somewhere downstream of the nozzle because of the interfacial forces between the jet and the surrounding air. When a liquid jet is discharged into air, disturbances on the jet surface will be augmented because of the aerodynamic interactions between the jet and the surroundings. Growth of these disturbances causes the liquid column to disintegrate into droplets soon after discharge [2]. If the diameter of the droplets exceeds some critical size, they tend to break into smaller droplets. These processes are referred to as primary and secondary break-ups. Obviously, when a water jet breaks up, its kinetic energy will be divided among many fine droplets and the jet loses efficient energy transfer, a pre-requisite in many applications (e.g. hydroentanglement or waterjet cutting).

The most commonly accepted jet disintegration classification in fluid mechanics literature was developed by Ohnesorge [3] who combined the Reynolds and Weber numbers and proposed a dimensionless Ohnesorge number Z (or Oh) [4].

$$
\begin{gathered}
\mathrm{Z}=\frac{\mu_{\mathrm{L}}}{\sqrt{\rho_{\mathrm{L}} \sigma \mathrm{d}_{\mathrm{j}}}}=W \mathrm{We}_{\mathrm{L}}^{0.5} \mathrm{Re}_{\mathrm{L}}^{-1} \\
W e=\frac{\rho V^{2} d}{\sigma} \\
\operatorname{Re}=\frac{\rho V d}{\mu}
\end{gathered}
$$

Equation 2

Where, $\mathrm{We}_{\mathrm{L}}$ is the liquid's Weber number, $\mathrm{Re}_{\mathrm{L}}$ is liquid's Reynolds number and $\mathrm{d}_{\mathrm{j}}$ is the liquid jet diameter at the nozzle exit. Based on Ohnesorge's work, Reitz suggested that 
there are four liquid jet break-up regimes which are presented in Figure 2 and Table 1 [4] and Derby stated that the criterion for a droplet to possess sufficient kinetic energy to be ejected from the nozzle is $\mathrm{We}_{\text {crit }} \geqslant 4$ or $\mathrm{Re} \leqslant 2 / \mathrm{Z}$ [5]. Therefore, generally speaking, a stable jet can be developed in the range $4 \leq \mathrm{We}_{\mathrm{L}}<8$.

As a two phase flow, the fibre suspension jet break-up regimes are likely to be different to the liquid only jets described in Figure 2 and Table 1. Figure 3 shows that the fibreliquid interaction and fibre-fibre interaction gives jets further types of instability although the Weber numbers are the same. The property of a fibre suspension is fully described by fibre length, the viscosity of dispersion media and fibre volume concentration and these factors will affect the design of fibre suspension jet stability experiments.

\subsection{Influences of nozzle design on the jet stability behaviour and fibre alignment}

Figure 4 shows four jets in which the Weber number, Ohnesorge number, Reynolds number and any other superficially defined quantities are approximately constant. The increasing nozzle aspect ratio from left to right make these jets display various break-up phenomena, though they are represented by the same point on Ohnesorge's graph (Figure 2) [6]. Thus, researchers have tended to approach improving the jet stability through adjusting the nozzle design. McCarthy and Molloy [6] examined the characteristics of various liquid jets from a laminar to a fully turbulent flow regime and presented expressions relating to their stability. Their main comments can be summarised as the major requirement of a nozzle being the efficient conversion of potential energy to kinetic energy. This is best achieved by a sudden, smooth contraction of the flow area from the supply line to the desired nozzle outlet diameter. In addition, the nozzle aspect ratio L/d has a significant effect on the initial jet velocity profile and subsequent jet surface shape up to $\mathrm{L} / \mathrm{d}$ values where the shear stress and static pressure gradient are fully developed. 
The variability of L/d offers a means of control of the jet surface roughness over a considerable range. Theobald [7] pointed out that a concave nozzle with a sudden smooth contraction in flow area from the nozzle inlet to the outlet consistently produced the best jet in terms of stability. Furthermore, a straight-sided nozzle which approached the axis at $30^{\circ}$ formed the best all round jet of a series of profiles and can exhibit better stability than that of the fire hose nozzle designed by Rouse [8]. Parsheh [9] discussed the fibre orientation in turbulent flow inside a planar contraction with different shapes and concluded that fibre orientation anisotropy is lower for contractions with low initial rate of strain. However, in Theobald's work, the convex nozzle which is a low initial strain rate contraction nozzle presents reduced jet stability, compared to that of a concave nozzle.

Although researchers have already undertaken much work on nozzle design for either improving jet stability or fibre alignment, there is still an absence of work on the combination of these effects. Experimental work with platen nozzles will therefore be used to validate whether the convex nozzle offers the best alignment quality compared to a straight sided nozzle and large aspect ratio straight sided nozzle. Furthermore, the fibre alignment performance of a concave nozzle will be explored in this paper and CFD simulated shear rate profile is used to explain the observed good stability behaviour of concave nozzles. The simulated nozzle geometries have been shown in Figure 5 and the CFD methodology is described in the following chapter. 


\section{Material and methods}

\subsection{Jet stability test}

As this study was inspired by the ultimate aim of improving the alignment quality in the hydrodynamic short fibre alignment process, the testing materials and conditions were selected according to their relevance to this process.

Stability testing of a glycerine/water solution jet has been undertaken to firstly confirm the liquid only jet (no fibres) break-up regime. Oleon Glycerine 4810 with glycerine content $\geq 99.5 \%$ was supplied by Univar UK. The glycerine was diluted with different wt $\%$ of tap water to achieve various viscosities. A Brookfield LVDVII viscometer was used to measure the viscosity and the temperature was also noted. The properties of the jet tested are listed in Table 2. The glycerine/water solution was fed into a pressure pot which has a convergent nozzle attached at the bottom (Figure 6). By adjusting the pressure level, a liquid jet was generated with different velocities and exhibited various jet break-up regimes. In addition, for each test, 50 images were captured sequentially by a camera to record the jet motion.

For the tests including fibres in suspension a glycerine/water solution was used as dispersion media. Tenax ${ }^{\circledR}$-A HT C124 carbon fibre staples coated with a water-soluble sizing, was supplied by Toho Tenax Europe GmbH. The fibre lengths were $3 \mathrm{~mm}$ and 12 mm. The fibre volume concentrations are listed in Table 3. The viscosities of the suspension were controlled by changing the temperature rather than the weight percentage of water in suspension, this was done to establish a consistent viscosity during mixing at room temperature which was required to achieve good dispersion. The Brookfield LVDVII viscometer was used to measure the effective viscosity of the fibre suspension. The stability test of fibre suspension jet followed the pure liquid jet testing 
procedure as described before. Finally, three aligned fibre tapes were made with jets in different break-up regimes to validate the influence from suspension jet stability on fibre alignment quality in a finished product.

\subsection{The effects of nozzle geometry on fibre alignment}

The profiles of the nozzles examined are shown diagrammatically in Figure 7, they fall into two groups, the first consisting of straight-sided profiles with different nozzle aspect ratios. The second group of curved nozzles consisted of a venturi-shaped nozzle [7] and a prototype concave profile based on modified design criteria for wind tunnel applications [10]. All these nozzles have a $70 \mathrm{~mm}$ inlet and $10 \mathrm{~mm}$ outlet which means they had been designed with the same overall contraction ratio. The nozzle shapes were made by waterjet cutting and then the thin flat nozzle was sandwiched between a machined aluminium plate (incorporating the inlet) and a clear acrylic window to allow observation of the internal behaviour of the nozzle. The pressure pot was filled with $3 \mathrm{~mm}$ Tenax ${ }^{\circledR}-\mathrm{A}$ HT C124 fibre suspension which has a $0.1 \%$ fibre volume concentration. Then constant pressure was supplied and the suspension flowed through a pipe which is attached at the bottom of the platen nozzle. A camera was set above the nozzle and parallel to the top surface. Thus, fibre motion in the contraction region and near the nozzle exit can be observed and recorded.

In parallel with this activity Ansys Fluent Computational Fluid Dynamics software was used to create a 2D simulation to explore the flow kinetics inside these nozzles (Figure 5). For these four nozzle simulations, triangular element mesh was used and the total number of elements for each case is of the order of 233000. The pressure based solver was used to simulate the laminar glycerine flow. The most important settings that have been applied are: 
- Boundary conditions: (1) Velocity inlet - the velocity components are described by a fully developed laminar flow velocity profile which was exported from the outlet of a 2D straight pipe (the diameter of pipe is same with the nozzle inlet) CFD simulation ( $2 \mathrm{~g} / \mathrm{s}$ mass flow inlet boundary condition, pressure outlet with 0 gauge pressure); (2) Pressure outlet - gauge pressure is 0; (3) Wall - no slip.

- Solution methods: (1) SIMPLE Scheme; (2) Spatial discretization: Gradient Least Squares Cell Based, Pressure - Second Order, Momentum - Second Order Upwind.

\subsection{Liquid jet break-up regime validation}

In hydrodynamic alignment processes, a low speed laminar jet is required to maintain the aligned orientation of fibre before the jet is deposited on the inner surface of the rotating drum. The Re number for the jet is always below 10 and $\mathrm{Oh}$ number is around 4 this depends on the fibre length and fibre volume concentration. Thus, according to the normal liquid jet break-up regimes, the break-up phenomenon of suspension jet is in the varicose regime but close to the boundary of dripping. Figure 8 shows the photo results of glycerine/water solution jet break-up phenomenon test. Photo $a_{1}$ and $b_{1}$ clearly show that the jets were dripping as the kinetic energy is not enough to generate a jet when $\operatorname{Re} \leqslant$ 2/Oh. When the liquid jet has a property, $4 \leq \mathrm{We}_{\mathrm{L}} \leq 8$, a smooth cylindrical jet was achieved as shown in photo $a_{2}$ and $b_{2}$. As the velocity was increased, the varicose behaviour is more pronounced (photo $a_{3}$ and $b_{3}$ ). When the data point is close to the midpoint between the Rayleigh regime and sinuous regime the varicose shape was clearly obtained (as shown in photo $b_{4}$ ). These results strongly agree with the jet stability curve which is discussed by many researchers and summarized by McCarthy and Molloy [11]. It suggests that 
when the viscosity and density are constant, the jet break-up length grows with the increasing velocity [11].

\subsection{Short fibre suspension exploration of jet break-up regime}

As described in the previous sections, the liquid jet break-up regime is based on the combinations of inertia of the liquid, surface tension and aerodynamic forces acting on the jet. However, for a short fibre suspension jet, more influencing factors need to be considered. In this section, the effects from different fibre lengths, fibre suspension concentrations and fibre suspension viscosities on fibre suspension jet break-up regimes are described.

Figure 9 shows that different fibre lengths can make the suspension jets behave with different stability phenomena. When the suspension viscosity is constant, the jet stability becomes worse with increasing Re number in common with the behaviour observed for the pure liquid jet described by the break-up regime in Figure 2. However, when the fibre volume concentration is constant, the fibre-fibre interaction in $12 \mathrm{~mm}$ fibre-containing suspension is more significant as the fibre aspect ratio is 4 times larger. Thus, if the fibre concentration, suspension viscosity and jet Re number are same, the use of $12 \mathrm{~mm}$ fibre can make the jet more unstable. On the other hand, by increasing the fibre concentration, the fibre-fibre interactions become greater although the fibre length is same. Thus, the photo results in Figure 10 validate that the greater the fibre-fibre interactions in the suspension, the more induced instability.

It was mentioned by Soderberg [12] that the waves on the jet surface are more homogeneous in the flow of a fibre suspension jet compared to the flow of a water jet. Also, it was found that the strength of the break-up of the jet was lower for the fibre suspension than for the pure water jet at the same flow rate. Thus, the presence of fibres in the water clearly has an impact on the stability of the jet. It can be surmised that not 
only the fibres but also their orientation distribution could affect the stability of suspension jet. In Figure 11, the photo results reveal that with fibre length and fibre concentration remaining the same, the stability of suspension jet was improved by reducing the viscosity of the dispersion medium. Short fibres rotate under the shear stress field with greater ease as the viscous forces become smaller. Then better alignment quality can be achieved which tends to be beneficial to the jet stability.

To validate the influence of jet stability on fibre alignment quality, three $2.5 \mathrm{gsm}$ tapes were manufactured with $3 \mathrm{~mm}$ Tenax ${ }^{\circledR}$-A HT C124 carbon fibre and a fibre volume concentration in the suspension of $0.05 \%$. The first tape (Figure 12_a) was made with a dripping jet $\left(\mathrm{We}_{\mathrm{L}}<4\right)$, fibres were bent and became bundles inside the droplet then deposited on the nylon mesh. When $\mathrm{We}_{\mathrm{L}}=10$, the jet behaves in a varicose way, fibre could be bent inside the jet near the varicose surface or even protrude as shown in Figure 1_d. At this varicose jet condition, the second tape was made, and the fibre orientation was shown in Figure 12_b. The third tape in Figure 12_c was manufactured with a jet which has a $\mathrm{We}_{\mathrm{L}}=6$. The fibre orientation is homogeneous and aligned with the flow direction.

Thus, it can be predicted that the stability of a fibre suspension jet will significantly affect the fibre alignment quality. Large fibre to fibre interaction in the jet will induce greater instability. On the other hand, good fibre alignment inside the nozzle can help to improve the jet stability and this can be achieved by judicious nozzle geometry design.

\subsection{The effects of nozzle geometries on fibre alignment}

In injection moulding process simulation, researchers have indicated that the fibre orientation is determined and affected by the flow kinematics [13] [14]. For instance, in a simple shear flow, the fibres tend to align along the velocity gradient. The hydrodynamic force makes the fibres located near the wall rotate until they reach an 
equilibrium state and become fully aligned with the velocity field. However, for those fibres located around the flow symmetry plane, the velocity gradient will decrease which results a zero-hydrodynamic force and an anisotropic fibre orientation.

In a converging channel elongational flow is also generated due to the flow acceleration. In the near wall region, shear flow is dominant, and the fibres tend to align in the flow direction. In the core region, the shear stress decreases, and the flow is dominated by extensional flow, thus the fibres tend to align along the flow direction.

To explore the effects of different nozzle geometries on the flow kinematics, the shear flow and elongational flow profiles in four different nozzle shapes (Figure 5) were evaluated by CFD simulation and following equations:

$$
\begin{gathered}
\dot{\varepsilon}=\frac{\mathrm{d} v_{x}}{\mathrm{dx}} \\
\dot{\gamma}=\frac{\mathrm{d} v_{x}}{\mathrm{dr}} \\
Q=\int v_{x} 2 \pi r d r
\end{gathered}
$$

Equation 1

Equation 2

Equation 3

Where, $\dot{\varepsilon}$ is the average elongational strain rate, $\dot{\gamma}$ is the shear strain rate, $v_{x}$ is axial velocity (flow direction), $\mathrm{Q}$ is the volume flow rate, $\mathrm{r}$ is the radius of nozzle and $\mathrm{x}$ is the nozzle length.

In Figure 13, the average shear strain rate (velocity gradient, ) and average elongational strain rate profiles in the original straight sided nozzle are plotted from nozzle inlet to the exit (nozzle length is $0 \mathrm{~m}$ at the nozzle inlet and the nozzle length is $0.077 \mathrm{~m}$ at the nozzle exit). Both shear strain rate and elongational strain rate keep increasing from the nozzle inlet to the exit because of the linearly increasing nozzle contraction ratio.

The flow characteristics in the long straight section nozzle are shown in Figure 14. The contraction ratio of this nozzle is 0.05 which is same as the straight sided nozzle. However, the length of the converging section is a third shorter than that of the straight sided nozzle. 
In the converging region $(0.02<$ nozzle length $<0.06 \mathrm{~m})$, the average shear strain rate and elongational strain rate keep increasing and have a sharp growth at the boundary between the converging section and straight section (nozzle length is $0.06 \mathrm{~m}$ ). When the flow enters the straight section, the average shear strain rate becomes constant $\left(3.17 \mathrm{sec}^{-1}\right)$ which is same as the value at the boundary position. However, the elongational strain rate shows a sharp decrease from 0.931 to $0.018 \mathrm{sec}^{-1}$ and then keeps constant. Thus, the flow in the straight section is shear flow dominated plug flow.

Figure 15 shows the average elongational strain rate and average shear strain rate profiles inside the convex nozzle. In the initial $7 \mathrm{~cm}$ of the nozzle, the convex profile makes the flow have higher shear strain rate compared to that of straight sided nozzle as the contraction ratio is greater. However, in the following section $(0.07<$ nozzle length $<0.077 \mathrm{~m}$ ), the contraction ratio tends to 1 and the contraction angle tends to $0^{\circ}$ (for a straight pipe, the contraction ratio is 1 and contraction angle is $0^{\circ}$ ) which leads to a reduction in flow acceleration. Thus, the flow elongational strain rate reduces gradually at the convex nozzle end region (nozzle length is between $0.07 \mathrm{~m}$ and $0.077 \mathrm{~m}$ ) and the average shear strain rate is smaller than that of the straight sided nozzle.

Inside the concave nozzle, along with the flow direction, both the average elongational strain rate and the average shear strain rate are increasing (Figure 16). The concave shape generates the smallest average shear strain rate at the nozzle exit comparing to the other three nozzles $(77 \%$ lower than the average shear strain rate at the exit of straight sided nozzle) and a high elongational strain rate which is only $24 \%$ smaller than the average elongational strain rate at the exit of the straight sided nozzle.

In addition, the ratio of the average elongational strain rate to the shear strain rate at these nozzle exit cross sections are plotted in Figure 17. The concave nozzle has an increasing contraction angle which makes the flow keep accelerating and obtain the highest ratio 
$(0.47)$ of the elongational strain rate to the shear strain rate at the nozzle exit. The original straight sided nozzle has a constant contraction angle which makes the flow at the nozzle exit behaving less elongational. The ratio of the elongational strain rate to the shear strain rate at the straight sided nozzle is 3 times smaller than the convex nozzle. The contraction angle of convex nozzle decreases from the nozzle inlet to the exit which means the flow at the nozzle exit is strongly dominated by shear. Thus, the ratio of the elongational strain rate to the shear strain rate at the convex nozzle exit is 0.013 (36 times smaller than the concave nozzle). Furthermore, in the long straight section, the contraction angle is 0 and the flow behaves as plug flow which makes the ratio of the elongational strain rate to the shear strain rate become the smallest among these four nozzles (78 times smaller than the concave nozzle).

To validate the effects of flow kinematics on fibre orientation, 2D platen straight sided nozzle, long straight sided nozzle, convex nozzle and concave nozzle (Figure 7_a-d) were used in the experimental work. The fibre orientation at the nozzle exit was captured, and the images are presented in Figure 18. The fibres in the concave nozzle show a highly aligned orientation (Figure 18_d). However, the shear dominated flow in the long straight nozzle makes the fibres misaligned (Figure 18_b).

The simulated results and experimental images indicate that the more elongational flow is generated in the nozzle, the more greatly aligned the fibre orientation distribution will be. The concave nozzle shape, with an increasing contraction angle, can improve the jet stability [7] and make the flow become elongational flow dominated at the nozzle exit which provides great aligned fibre orientation in the jet. 


\section{Conclusion}

The stability of fibre suspension jets has a significant influence on fibre alignment quality in processes requiring high fibre packing efficiency. The pure liquid jet break-up regimes can be used to describe the behaviour of a suspension jet and when $4 \leqslant \mathrm{We}_{\mathrm{L}} \leqslant 8$, a smooth cylindrical jet was achieved. However, nozzle geometry, fibre to fibre interaction and fibre orientation inside the nozzle are important factors in determining jet stability. The jet which is generated by a concave nozzle profile presents higher stability. Furthermore, the appropriate increment of contraction angle makes the flow become elongational flow dominated which generates a highly aligned fibre orientation. Meanwhile, this homogenous fibre orientation will be beneficial to maintain jet stability.

\section{Acknowledgements}

The authors gratefully acknowledge the support of the Boeing Company under the Boeing / University of Nottingham strategic collaboration in carbon fibre recycling.

\section{References}

[1].A.K. Salariya, J.F.T. Pittman, Preparation of aligned discontinuous fiber pre-pregs by deposition from a suspension, Polym Eng Sci, 20 (12) (1980), pp. 787-797

[2].Lefebvre AH (1989) Atomization and sprays. Hemisphere Publishing Corporation, New York

[3]. Ohnesorge W 1936 ZAMM - J Appl Math Mech 16 355-8

[4].Reitz R and Bracco F 1986 Encyclopedia of Fluid Mechanics: Gas Fluid Flows 23349 
[5].Derby B 2010 Annu Rev Mater Res 40 395-414

[6].M. J. McCarthy, Ph.D. Thesis, Univ. of Newcastle, N.S.W., Australia, 1972.

[7].C. Theobald, The effect of Nozzle design on the stability and performance of turbulent water jets, Fire Safety Journal, Volume 4, Issue 1, 1981, Pages 1-13, ISSN 0379-7112

[8].H. Rouse et al., Experimental investigation of fire monitors and nozzles, Trans. Am. Soc. Civ. Eng., 117 (1952) 1147

[9].M. Parsheh, M.L. Brown, C.K. Aidun, Variation of fiber orientation in turbulent flow inside a planar contraction with different shapes, International Journal of Multiphase Flow, Volume 32, Issue 12, December 2006, Pages 1354-1369, ISSN 0301-9322

[10]. L. G. Whitehead, L. Y. Wu and M. H. L. Waters, Contracting ducts of finite length, Aeronaut. Q., 2 (1951) 254 - 271

[11]. M. J. McCarthy and N. A. Molloy, Review of stability of liquid jets and the influence of nozzle design, Chem. Eng. J., 7 (1974) 1 - 20.

[12]. Soderberg, L. D. 1999, A comparison between the flow from a paper machine headbox and a low Reynolds number water jet. In Tappi Engineering Conference, Anaheim.

[13]. Bay, R.S., 1991. Fiber orientation in injection molded composites: A comparison of theory and experiment. Ph.D Thesis, Department of Mechanical Engineering, Urbana-Champaign, USA

[14]. Sadabadi, H. and M. Ghasemi, 2007. Effects of some injection molding process parameters on fiber orientation tensor of short glass fiber polystyrene composites (SGF/PS). J. Reinf. Plast. Compos., 26: 1729-1741 
Table 1 Expressions for break-up regimes [2]

\begin{tabular}{ll}
\hline Regime & Range \\
\hline Rayleigh (varicose) & $\mathrm{We}_{\mathrm{L}} \geqslant 8$ and $\mathrm{We}_{\mathrm{g}}<0.4$ \\
First wind-induced (sinuous) & $1.2+3.41 \mathrm{Z}^{0.9}<\mathrm{We}_{\mathrm{g}}<13$ \\
Second wind-induced & $13<\mathrm{We}_{\mathrm{g}}<40.3$ \\
Atomization & $\mathrm{We}_{\mathrm{g}}>40.3$ \\
\hline
\end{tabular}

Table 2 The calculated properties of glycerine/water solution

Glyc. \% Wt. Viscosity Temperature Glyc./Water Solution Density

\begin{tabular}{cccc}
\hline$\%$ & $\mathrm{mPa} \cdot \mathrm{s}$ & ${ }^{\circ} \mathrm{C}$ & $\mathrm{kg} / \mathrm{m}^{3}$ \\
\hline 97.1 & 1250 & 15.9 & 1258.8 \\
96.8 & 830 & 19.9 & 1255.4 \\
94.4 & 560 & 17.6 & 1246.7 \\
86.1 & 185 & 14.7 & 1221.7 \\
\hline
\end{tabular}


Table 3 Fibre suspension properties

\begin{tabular}{|c|c|c|c|c|c|}
\hline $\begin{array}{l}\text { Fibre } \\
\text { length }\end{array}$ & $\begin{array}{l}\text { Fibre volume } \\
\text { concentration }\end{array}$ & Viscosity & Temperature & $\frac{1}{\text { Fibre aspect ratio }}$ & $\begin{array}{c}\text { Fibre } \\
\text { suspension } \\
\text { concentration } \\
\text { regime }\end{array}$ \\
\hline $\mathrm{mm}$ & $\%$ & $\mathrm{mPa} \cdot \mathrm{s}$ & ${ }^{\circ} \mathrm{C}$ & I & I \\
\hline \multirow[b]{2}{*}{3} & 0.05 & 2450 & 4.5 & 0.0023 & $\begin{array}{c}\text { Semi- } \\
\text { concentrated }\end{array}$ \\
\hline & 0.1 & $\begin{array}{c}1350 \\
350 \\
2445\end{array}$ & $\begin{array}{c}43.5 \\
21.8 \\
6.5\end{array}$ & 0.0023 & $\begin{array}{l}\text { Semi- } \\
\text { concentrated }\end{array}$ \\
\hline 12 & 0.05 & $\begin{array}{l}1550 \\
380 \\
2355 \\
1585\end{array}$ & $\begin{array}{c}20.2 \\
43.5 \\
4.5 \\
20.8\end{array}$ & 0.00058 & $\begin{array}{c}\text { Semi- } \\
\text { concentrated }\end{array}$ \\
\hline
\end{tabular}



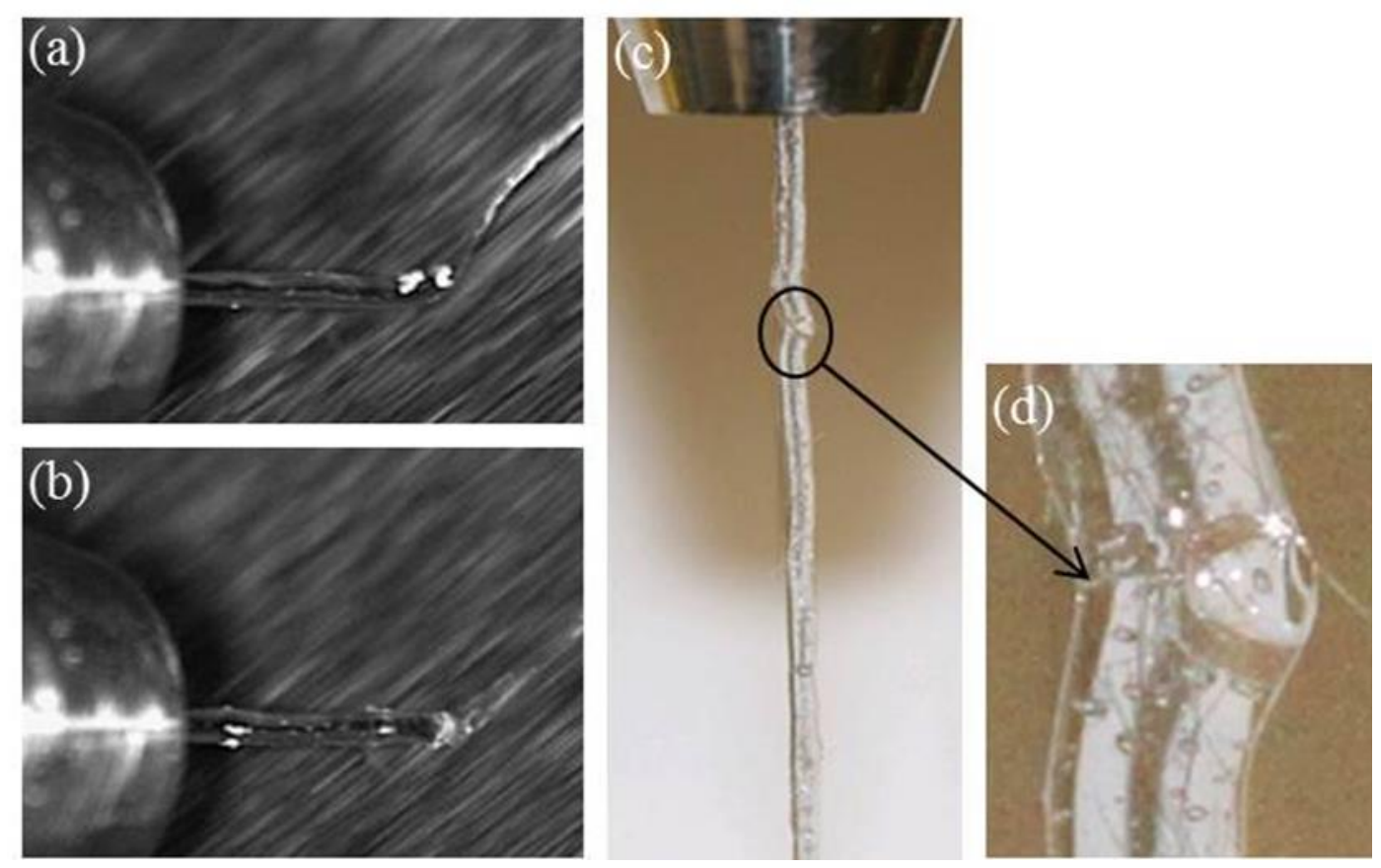

Figure 1 Photos of unsatisfactory fibre suspension jets - (a) unstable bouncing jet depositing on the fibre tape surface which leads to a poorly controlled fibre orientation; (b) varicose jet shape may splash on the tape which will damage the fibre orientation; (c) jet containing air bubbles; (d) air bubbles damage the smooth jet surface and fibres protrude at the air bubble.

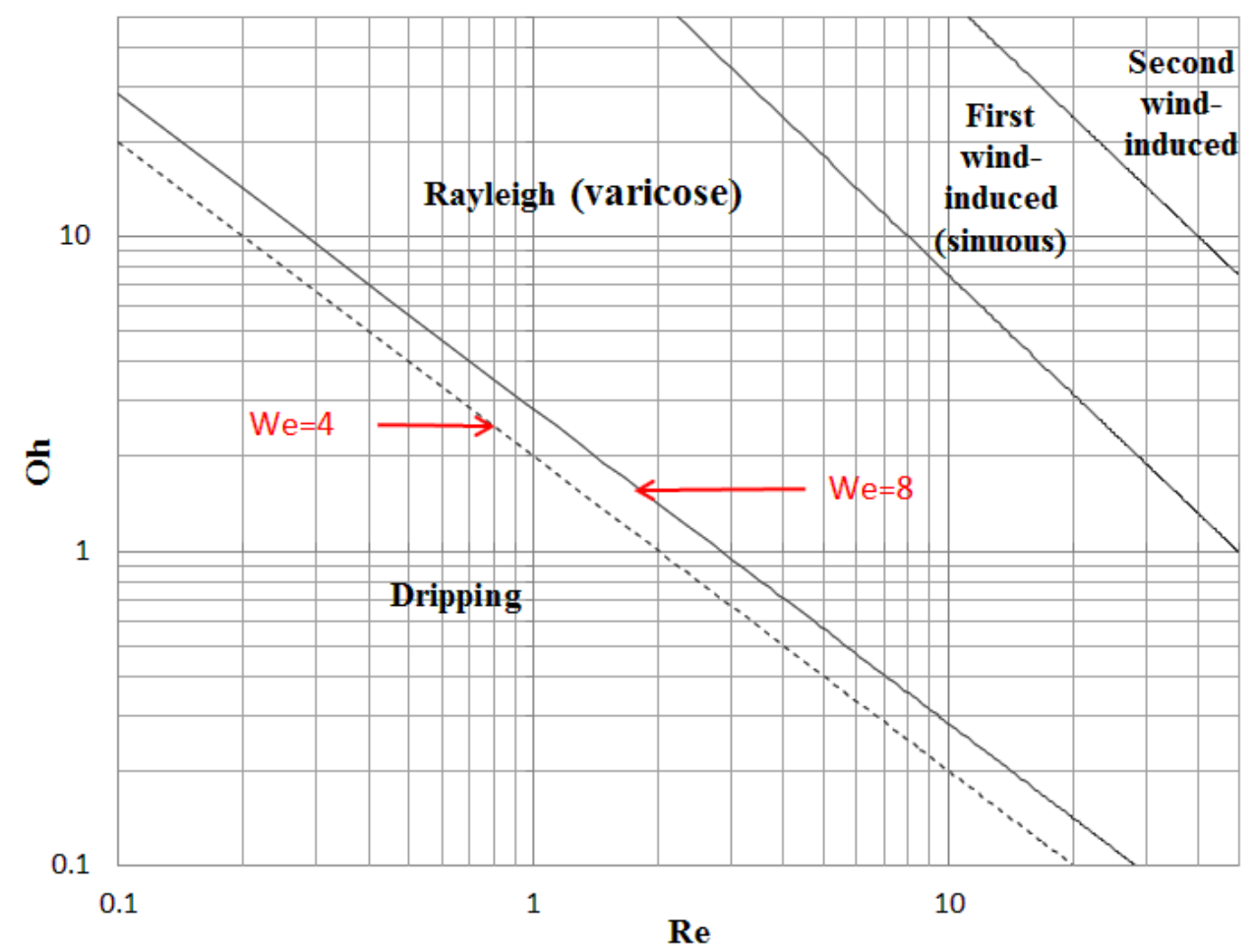

Figure 2 Classification of the modes of liquid jet disintegration [2] 

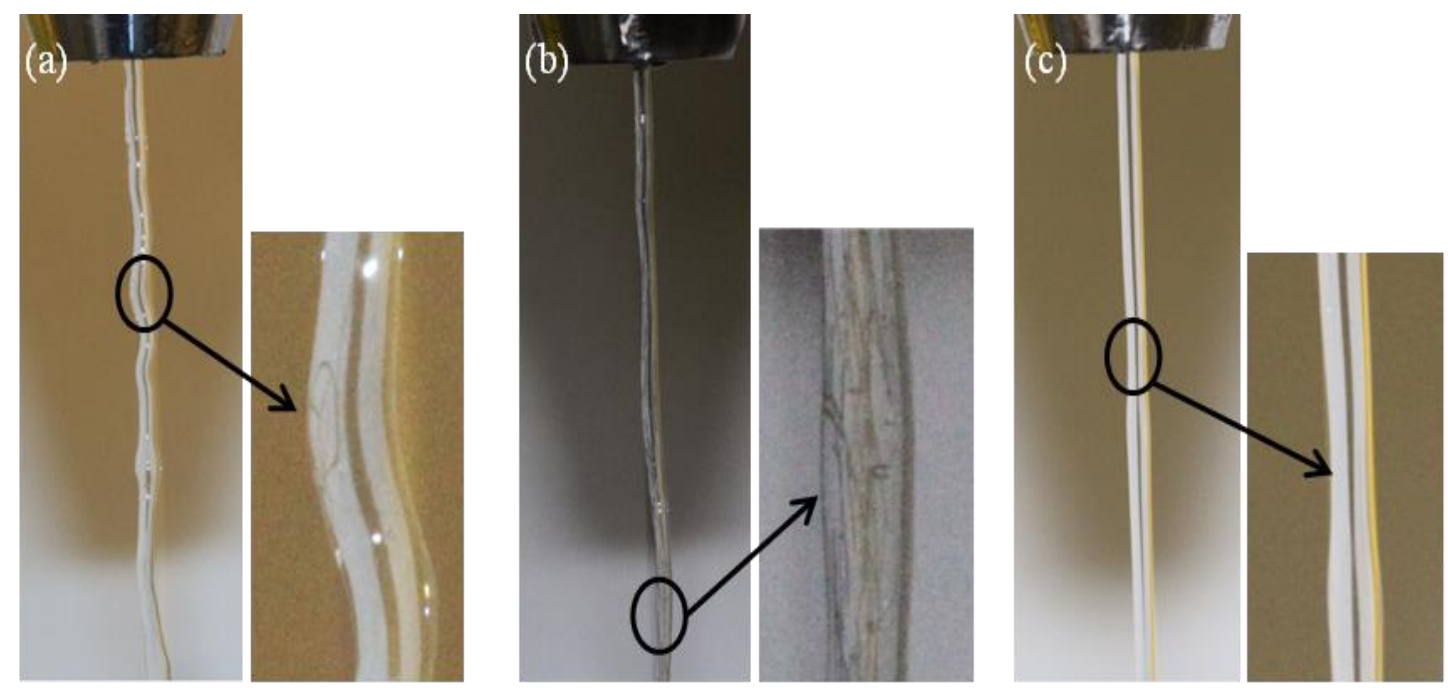

Figure 3 Images of fibre suspension jets and glycerine/water jets all at the same Weber number: (a) $12 \mathrm{~mm}$ length fibre_0.05\% volume fibre concentration jet - the fibre becomes disturbed in the wavy jet; (b) 3mm length_0.15\% volume fibre concentration - fibre suspension jet and fibres are aligned with flow direction; (c) glycerine/water solution jet behaves slightly varicose.
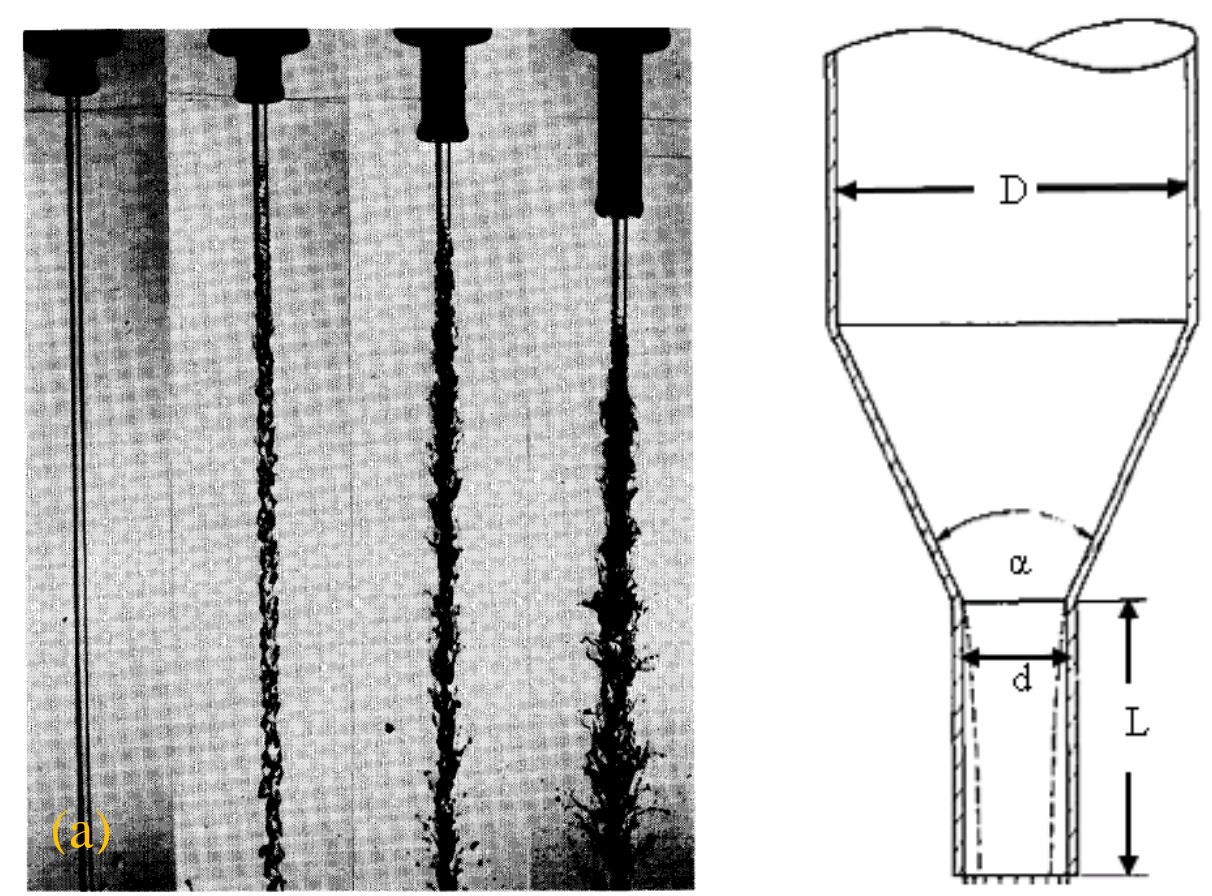

Figure 4 Different nozzle aspect ratios affect the stability of glycerol-water jets [5]. (a) Experimental work by Derby [5] validated that increasing the aspect ratio of nozzle will change the jet break-up behaviour. (b) A description of nozzle geometry properties (nozzle contraction ratio $=\mathrm{d} / \mathrm{D}$, nozzle aspect ratio $=\mathrm{L} / \mathrm{d}$, contraction angle $=\alpha)$. 

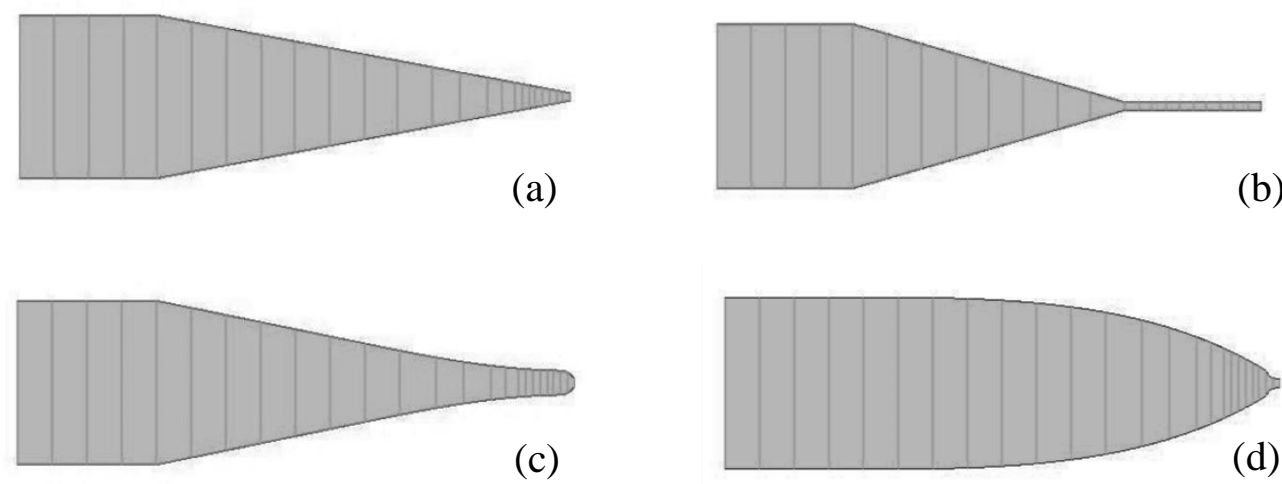

Figure 5 Geometries of nozzles which were used in CFD simulation: (a) the original straight sided nozzle; (b) the straight sided nozzle with aspect ratio $=25$; (c) the convex nozzle; (d) the concave nozzle. (the inlet, outlet and nozzle length dimensions of all these nozzles are same respectively)

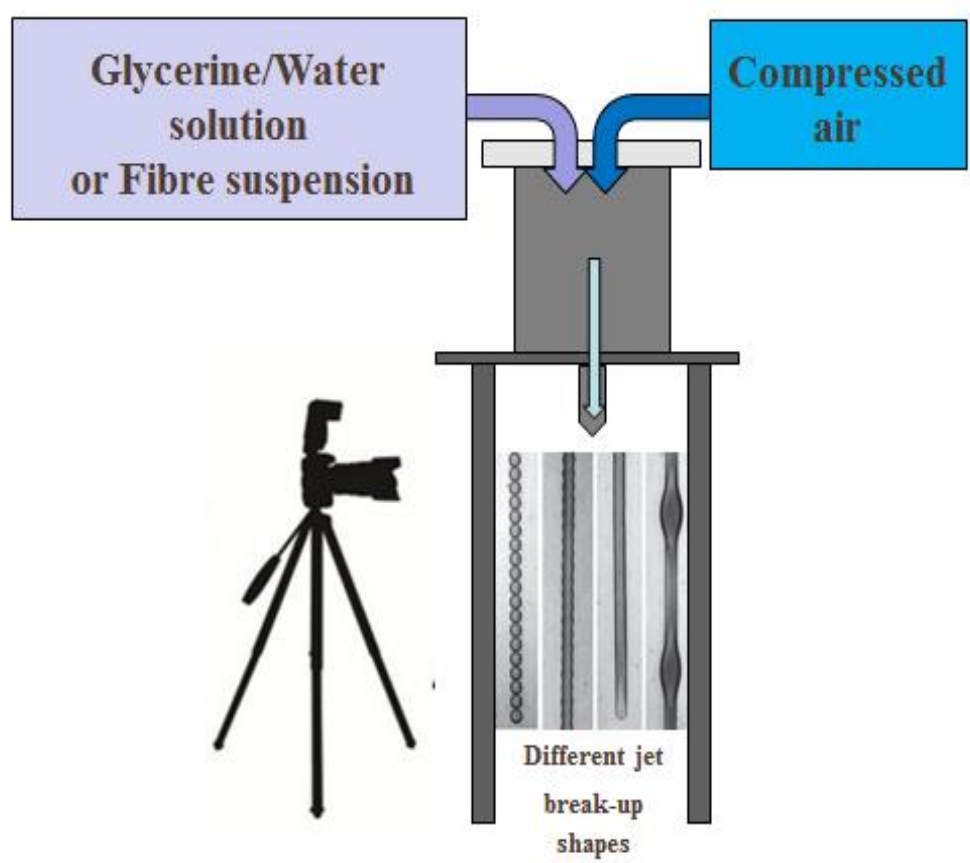

Figure 6 The experimental set-up of the jet break-up regime test 

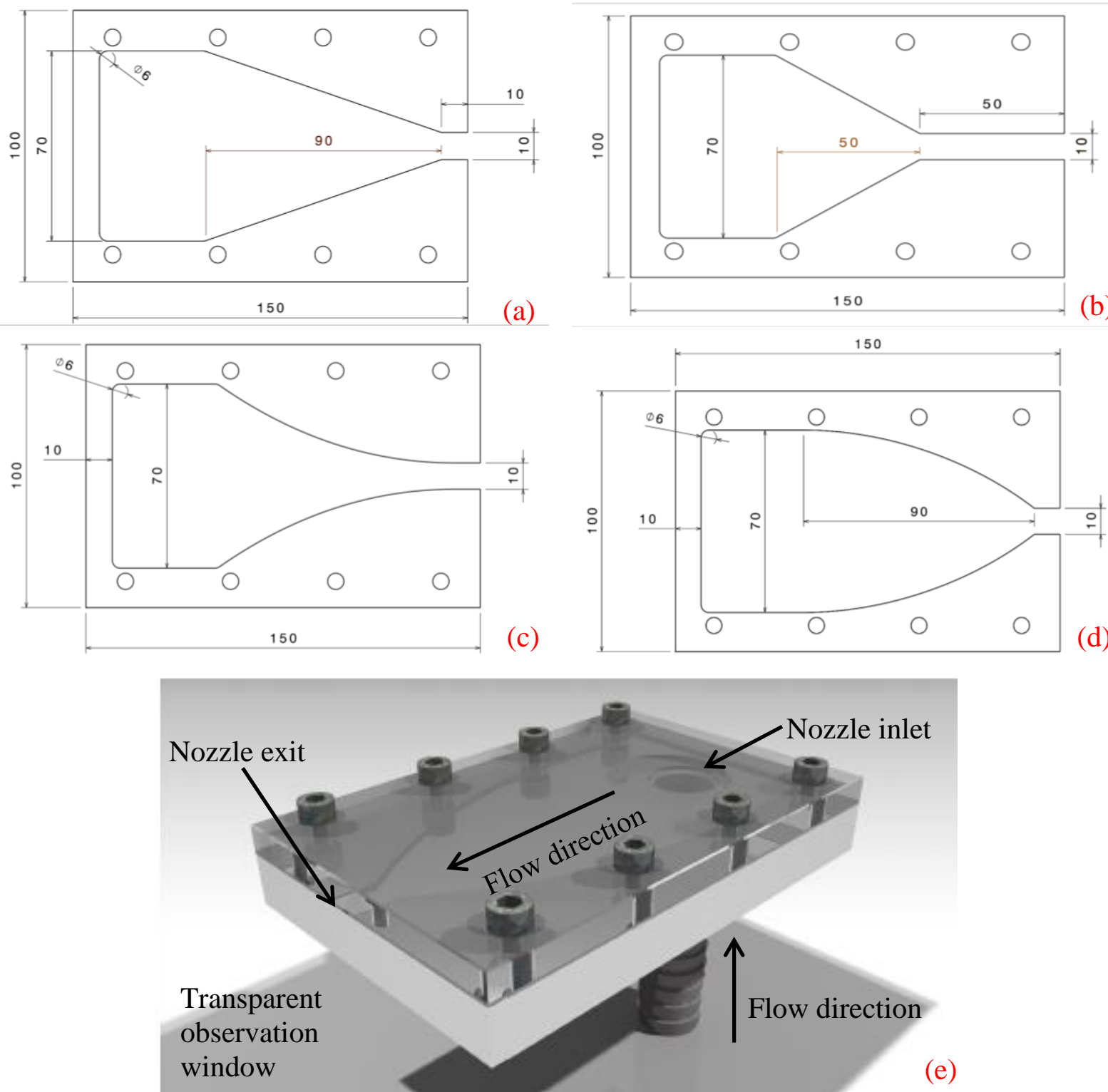

Figure 7 Geometries of platten nozzles and schematic diagram of testing rig. (a) original straight sided nozzle; (b) straight sided nozzle with aspect ratio $=25$; (c) convex nozzle; (d) concave nozzle; (e) schematic diagram of testing rig. 

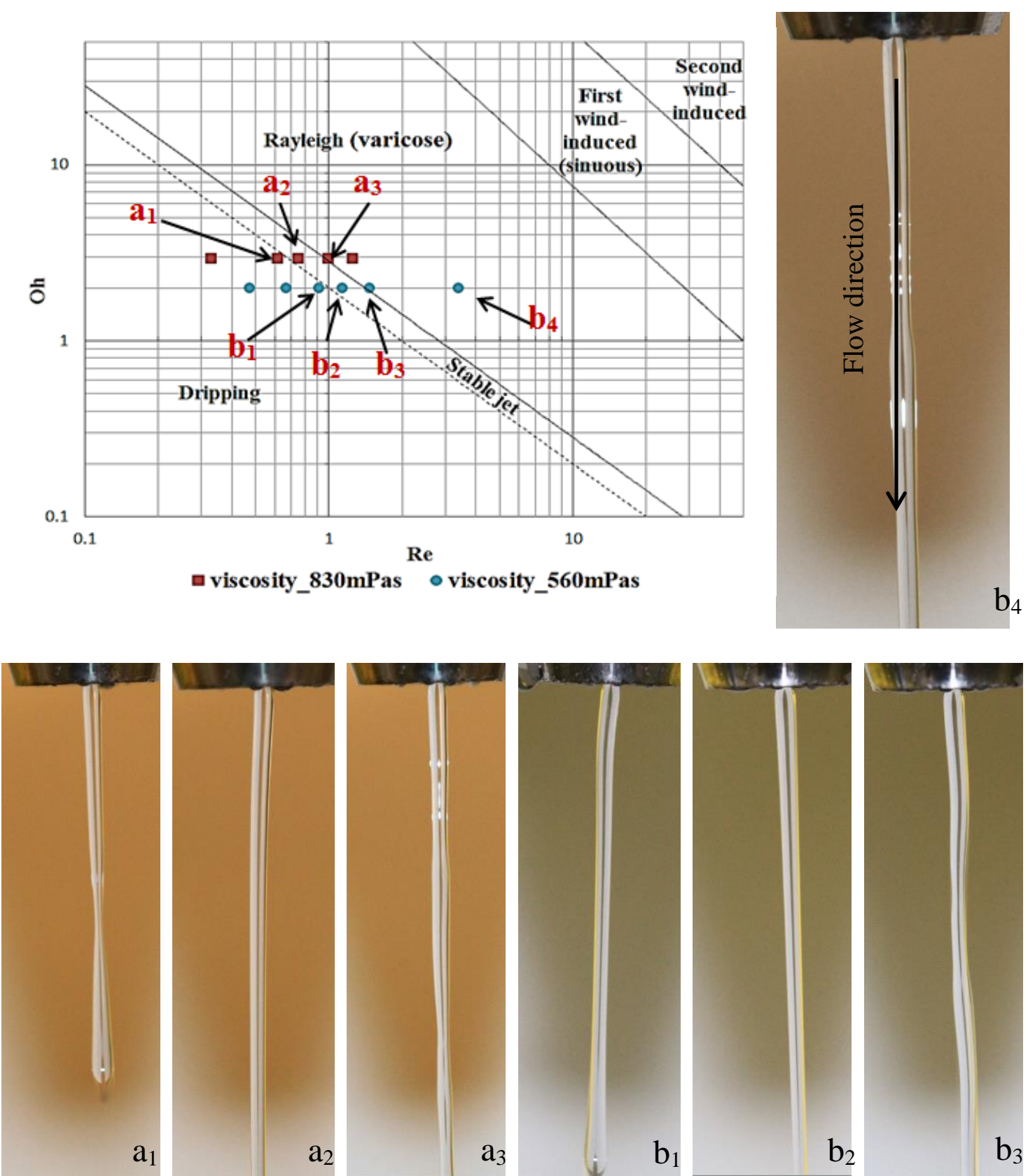

Figure 8 Image results of glycerine-water jet stability test 

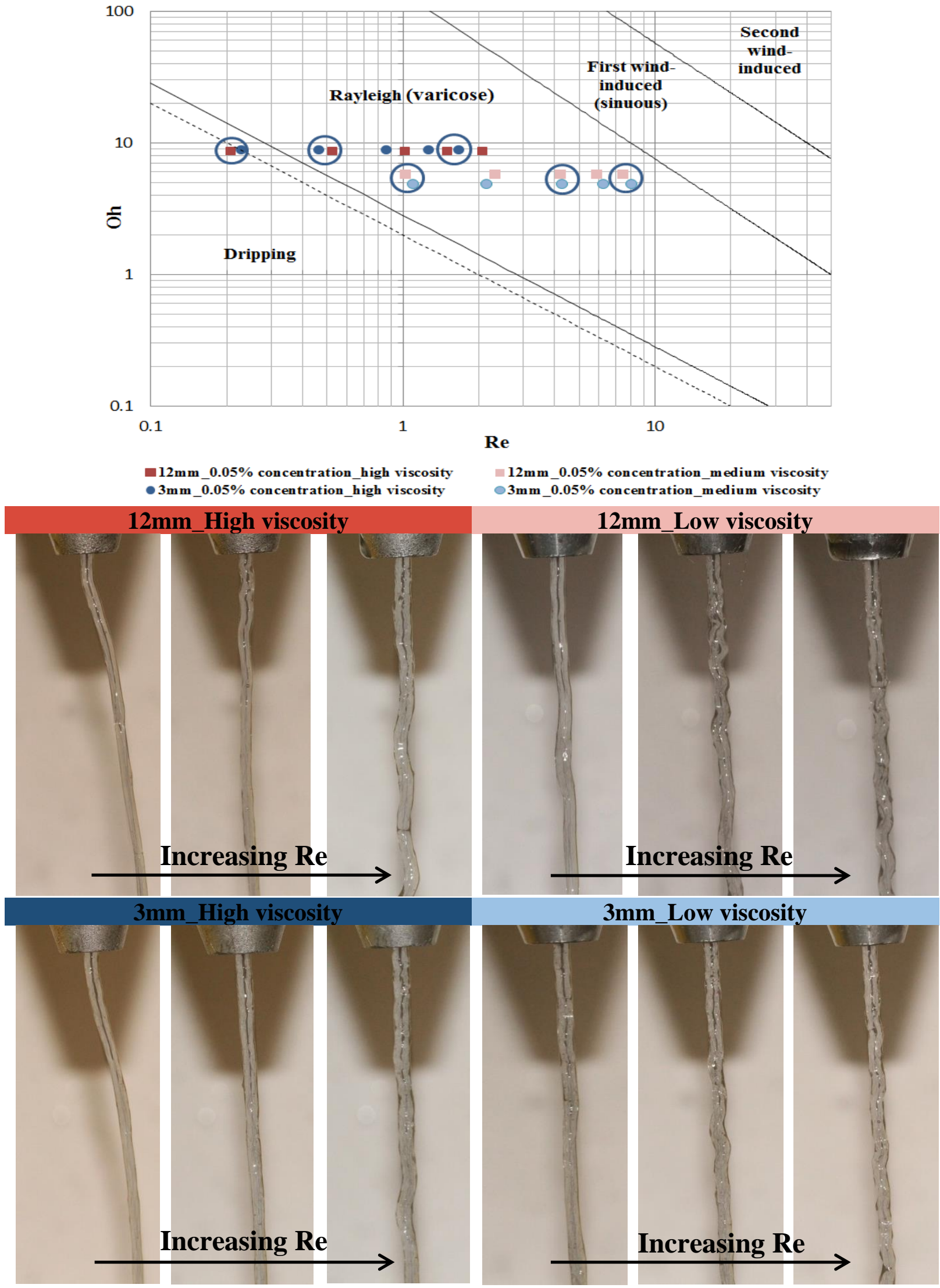

Figure 9 Image results of fibre suspension jets stability test - influence of different fibre lengths 

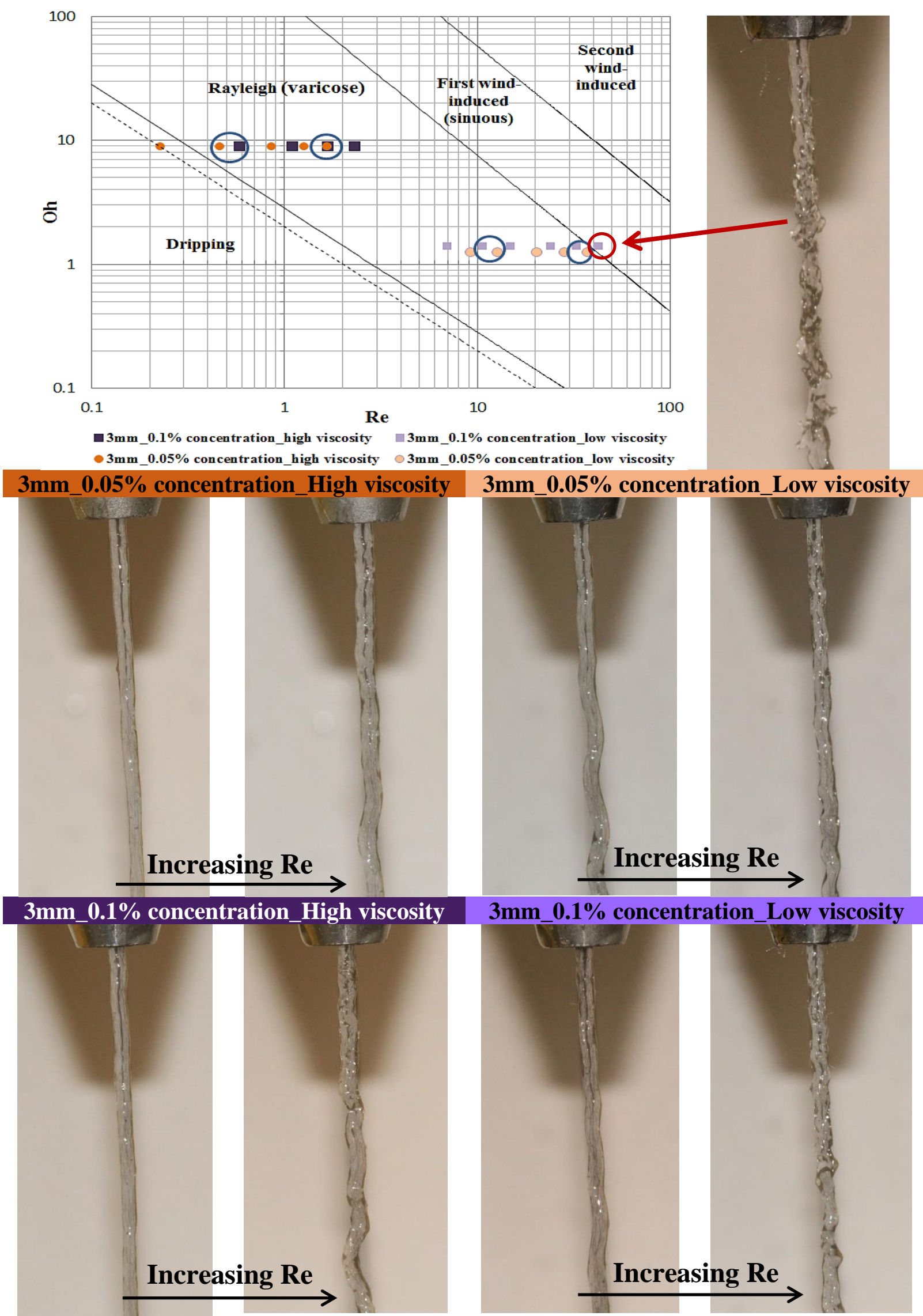

Figure 10 Image results of fibre suspension jets' stability test - influences of different fibre volume concentrations 

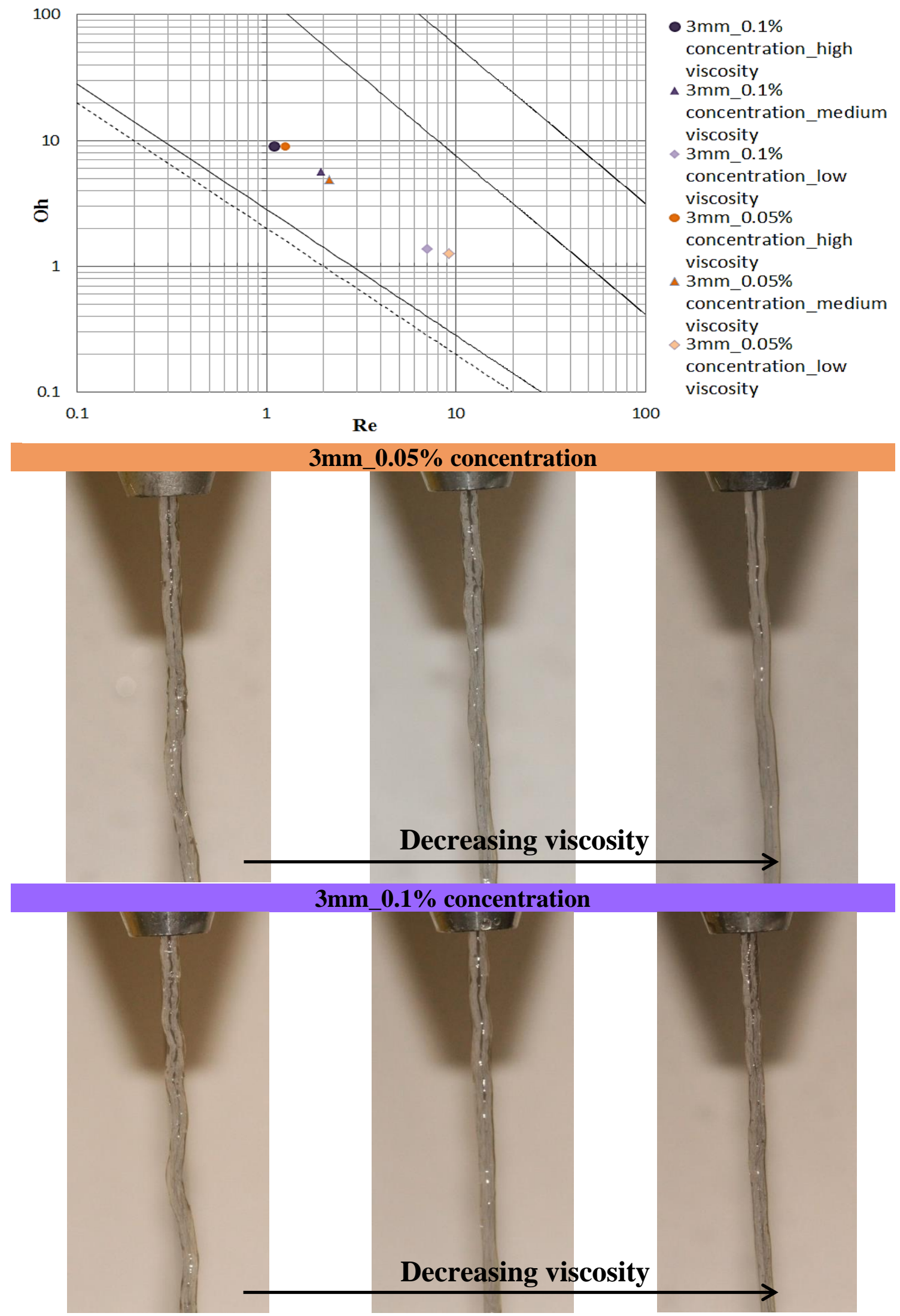

Figure 11 Image results of fibre suspension jet stability testing - influence of different viscosities of fibre suspension 

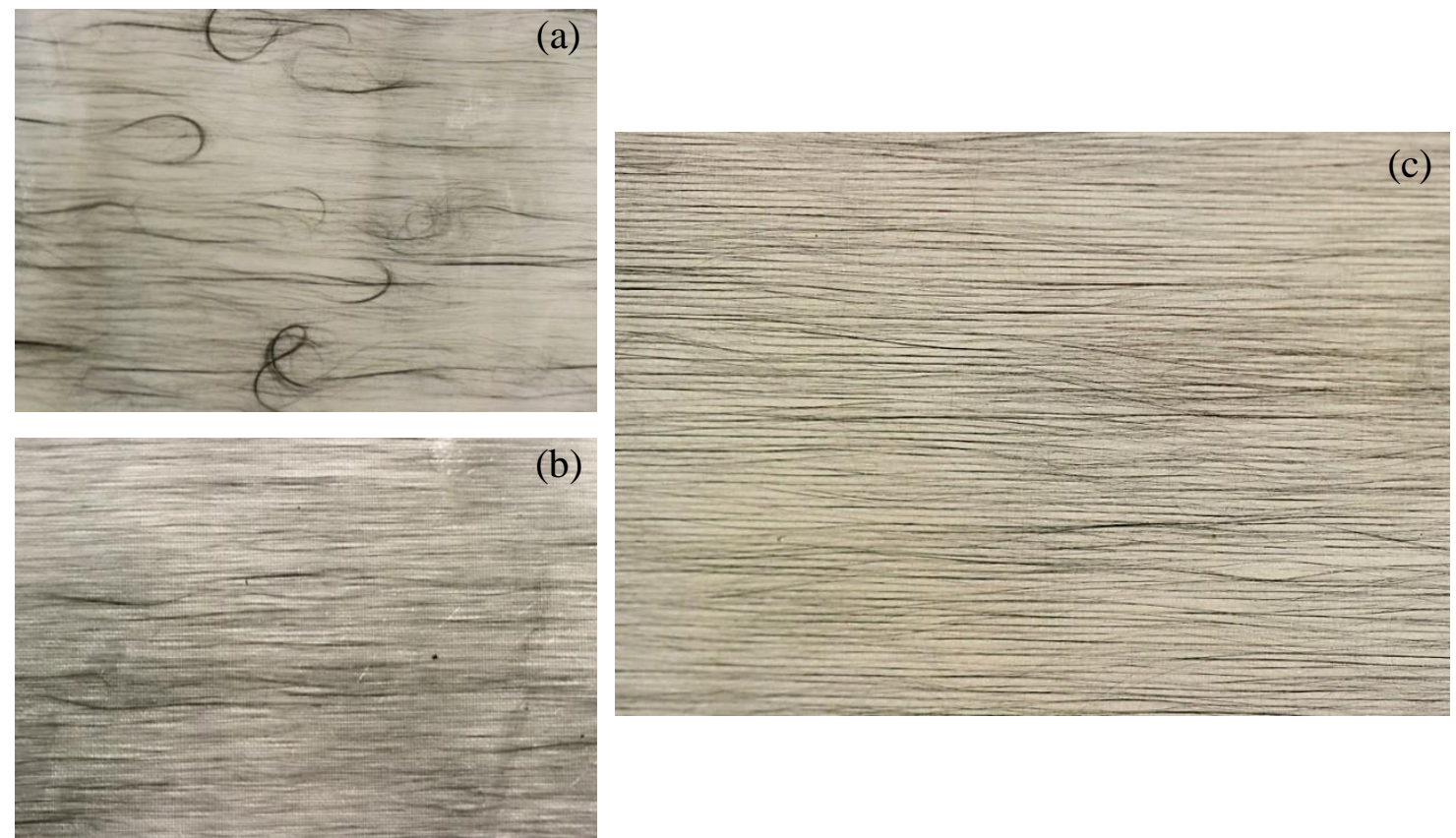

Figure 12 The effects of fibre suspension stability on the alignment quality: (a) tape made with dripping jet, $\mathrm{We}_{\mathrm{L}}<4$; (b) tape made with unstable jet in the varicose regime, $\mathrm{We}_{\mathrm{L}}=10$; (c) tape made with stable jet, $\mathrm{We}_{\mathrm{L}}=6$
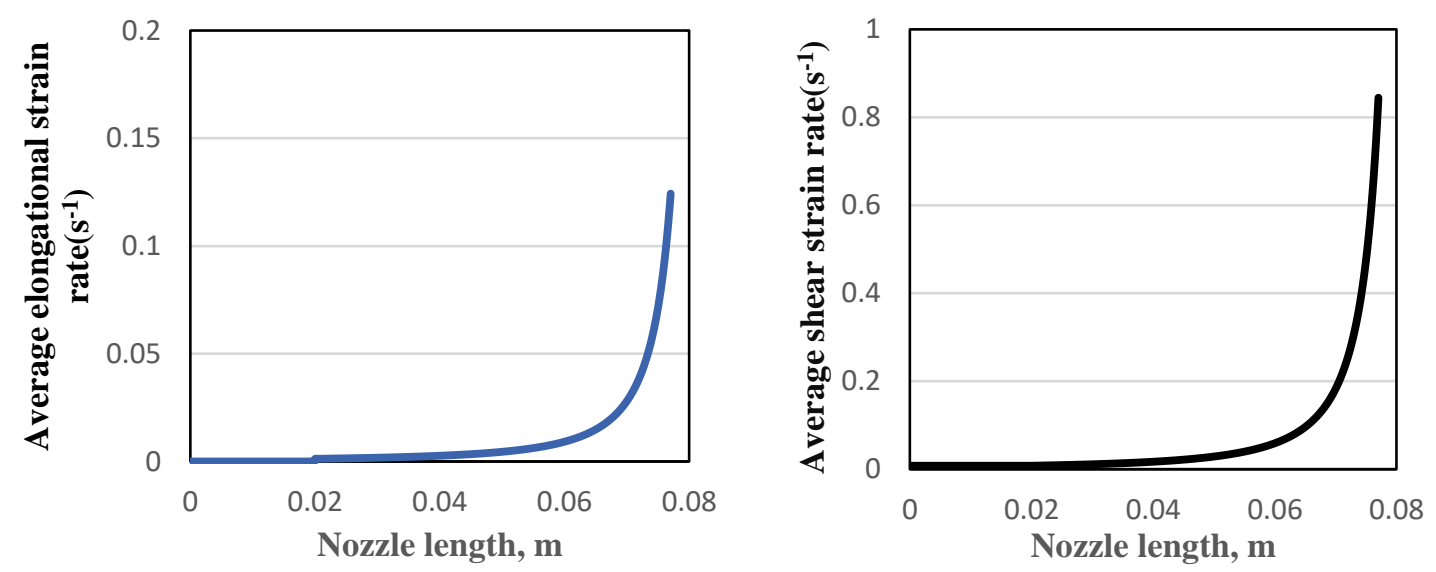

Figure 13 Plot of average elongational strain rate and shear strain rate at each cross section inside the original straight sided nozzle (type a) 

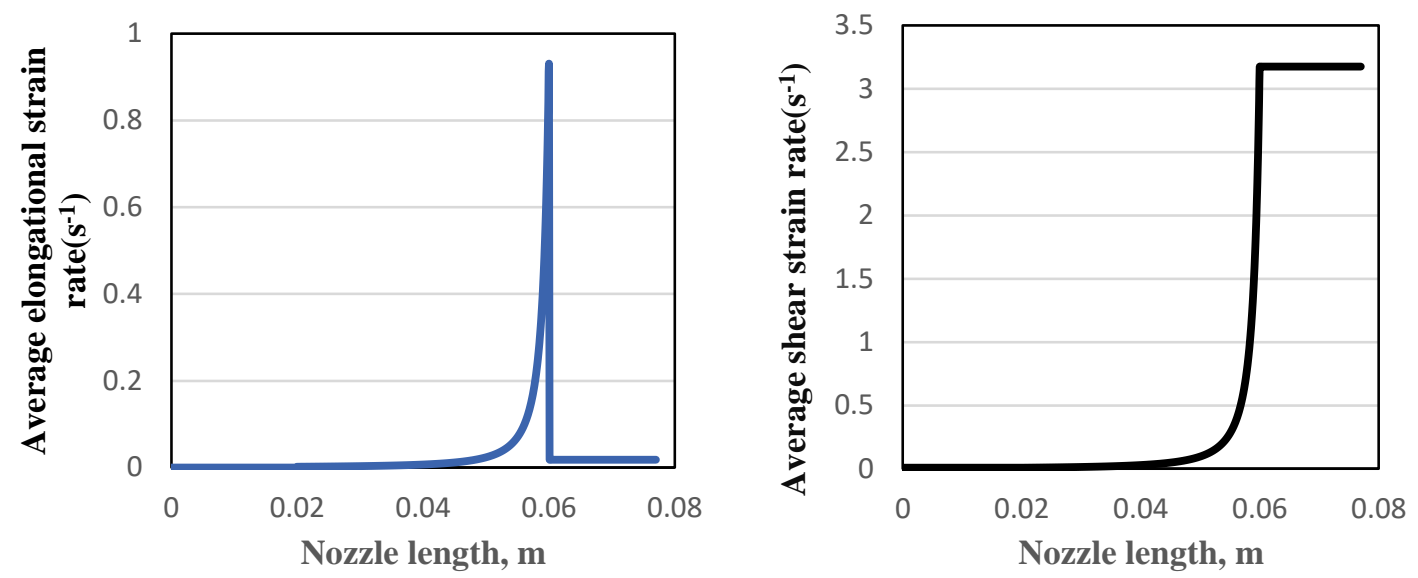

Figure 14 Plot of average elongational strain rate and shear strain rate at each cross section inside the long straight section nozzle with aspect ratio $=25$ (type b)
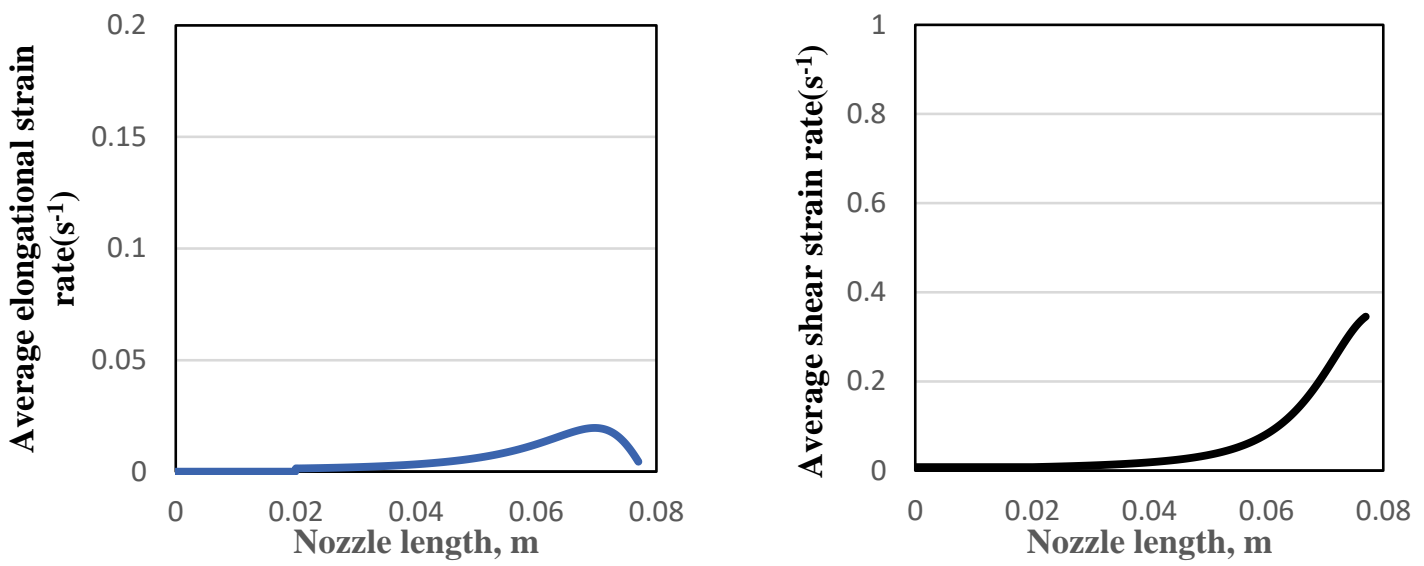

Figure 15 Plot of average elongational strain rate and shear strain rate at each cross section inside the convex nozzle (type c)
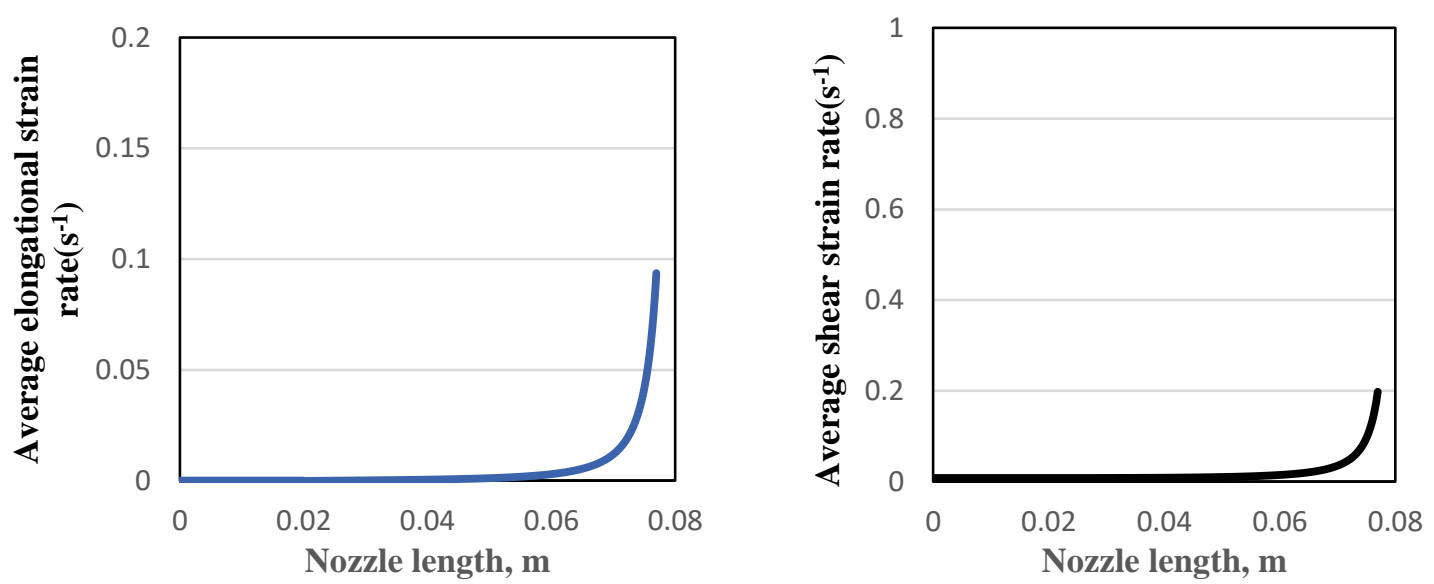

Figure 16 Plot of average elongational strain rate and shear strain rate at each cross section inside the concave nozzle 


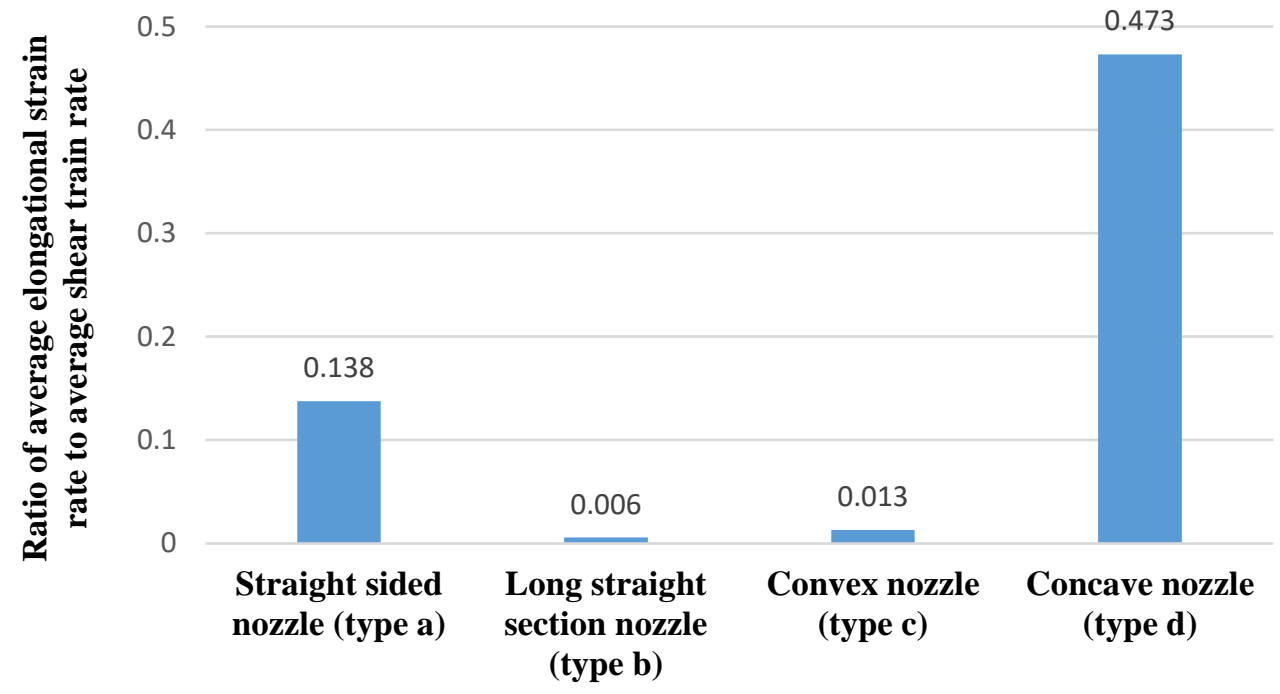

Figure 17 The ratio of average elongational strain rate to shear strain rate at the nozzle exit cross section 


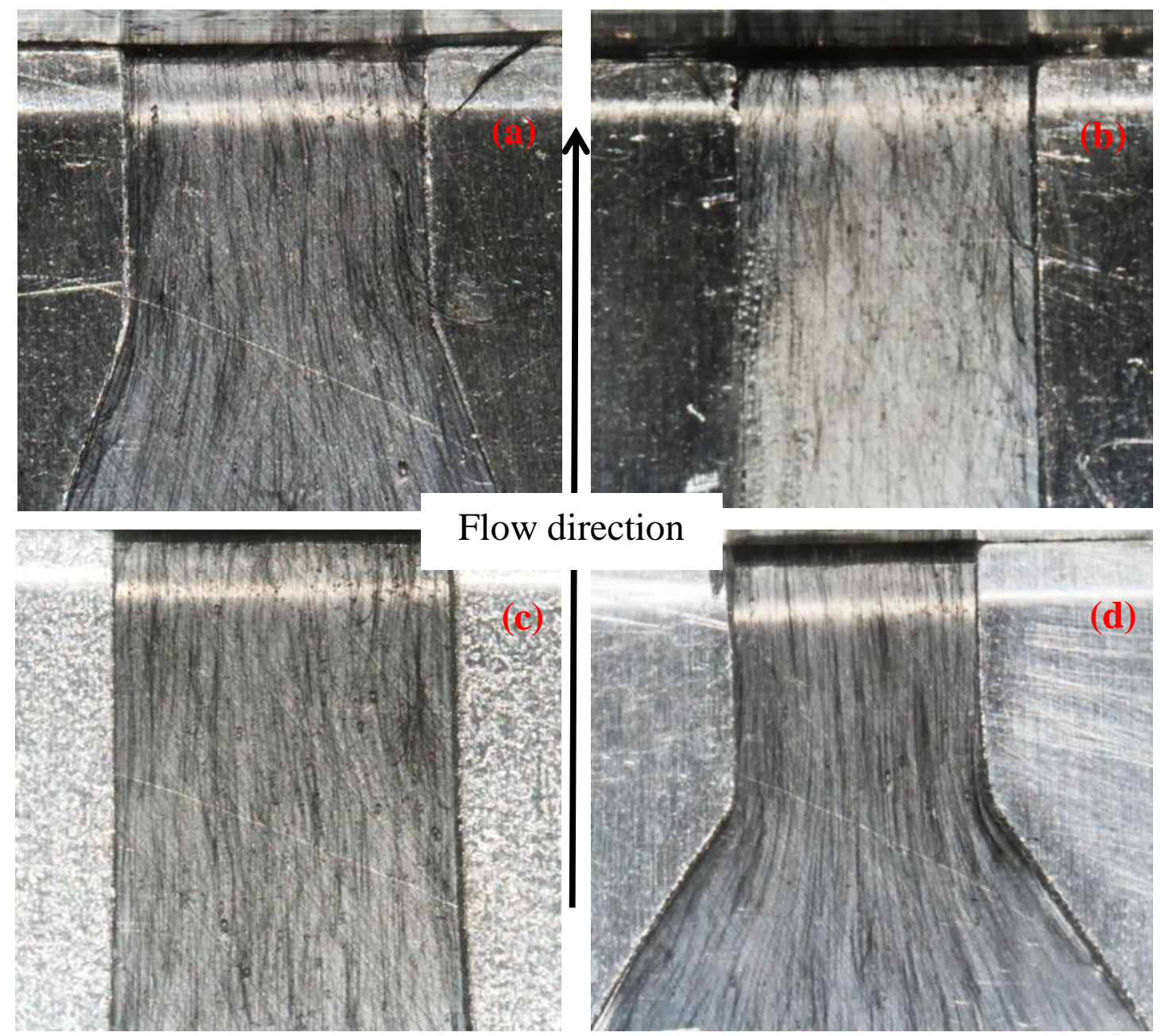

Figure 18 Fibre orientation distributions in different platten nozzles: (a) original straight sided nozzle; (b) straight sided nozzle with a aspect ratio=25; (c) convex nozzle; (d) concave nozzle. 